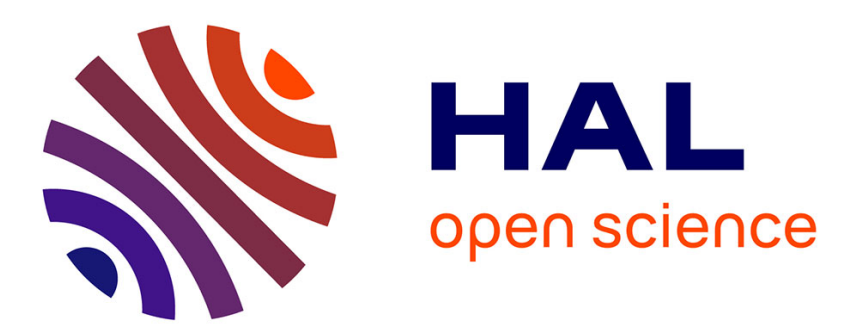

\title{
Design of a Haptic Magnifier using an Ultrasonic Motor
}

Frédéric Giraud, Michel Amberg, Christophe Giraud-Audine, Betty

Lemaire-Semail

\section{To cite this version:}

Frédéric Giraud, Michel Amberg, Christophe Giraud-Audine, Betty Lemaire-Semail. Design of a Haptic Magnifier using an Ultrasonic Motor. Eurohaptics 2014, Jun 2014, Versailles, France. pp.453459, 10.1007/978-3-662-44193-0_57 . hal-01043960v2

\section{HAL Id: hal-01043960 https://hal.science/hal-01043960v2}

Submitted on 7 Sep 2015

HAL is a multi-disciplinary open access archive for the deposit and dissemination of scientific research documents, whether they are published or not. The documents may come from teaching and research institutions in France or abroad, or from public or private research centers.
L'archive ouverte pluridisciplinaire HAL, est destinée au dépôt et à la diffusion de documents scientifiques de niveau recherche, publiés ou non, émanant des établissements d'enseignement et de recherche français ou étrangers, des laboratoires publics ou privés. 


\title{
Design of a Haptic Magnifier using an Ultrasonic Motor
}

\author{
Frédéric Giraud $^{a, b}$, Michel Amberg ${ }^{a, b}$, Christophe Giraud-Audine ${ }^{a, c}$, and \\ Betty Lemaire-Semail ${ }^{a, b}$ \\ ${ }^{a}$ Laboratoire d'Electrotechnique et d'Electronique de Puissance de Lille \\ ${ }^{b}$ University Lille1, Avenue Paul Langevin, F59000 Villeneuve d'Ascq, France \\ ${ }^{c}$ Arts \& Métiers ParisTech, Boulevard Louis XIV, F59000 Lille, France \\ \{frederic.giraud, michel.amberg, betty.semail\}@univ-lille1.fr \\ christophe.giraud-audine@ensam.eu \\ http://www.12ep.univ-lille1.fr
}

\begin{abstract}
The paper presents a serial architecture of an actuated manipulator which uses an ultrasonic motor. The serial architecture allows to modify the kinetic relationship between user's input and a tool. The design of the device is presented. A load, which exhibits fine details, is used in order to show how a zooming effect of its haptic rendering can be achieved with the haptic magnifier. Finally, the design is validated through an experimental analysis.
\end{abstract}

Keywords: Haptic, force-feedback, ultrasonic motor, piezoelectricity

\section{Introduction}

Human Controlled robots can be used to assist a Human user during manipulation tasks, when both the user and the robot hold a tool. By controlling the robot, some features can be programmed to facilitate the task from the user's point of view. For example, in [1], an actuated manipulator allows a packer to lift an object with low effort. In this application, the robotic arm reduces the amount of power required by the human user to move a heavy load, by magnifying the force he or she exerts, a technology named extender [2]. In [3], the authors report on a steady hand robot where the surgeon and the robot both hold the tool in a retinal microsurgery application. The robot filters out surgeon's tremor to achieve a better operation and reduce the rate of surgical complications. In [4], a robot assists in an arc welding task. The worker moves the welding torch, while the robotic assistant controls the displacement speed and the welding angles. In this particular applications, the assistance does not necessarily produce power. Instead, it modifies and improves user's trajectory.

Power assist or motion control robots often work in parallel with the user: the robotic assistance and the user's hand both have the same speed and position, and they share the required force[5]. To extend the capability of a user to manipulate a pay-load, user's force is magnified by the robot. The kinetic relationship between the user's hand and the tool is fixed, but the force-feedback is modified due to the assistance. 
The goal of the haptic magnifier detailed in this paper is to facilitate more acurate task performance in small scale movements. In these applications, the user can exert the required amount of force, but he or she may have a limited dexterity to move the tool with precision. Hence, it is a problem of displacement, rather than a problem of force. This is why, the device changes the kinetic relationship: the displacement of the tool is a function of the displacement of the user's hand. However, due to its construction, the force produced by the user is equal to the force on the tool. Hence, the next section of the paper presents the working principle of the haptic magnifier. Then the design of our prototype is presented, to finally conclude with some experimental results.

\section{Principle of the haptic magnifier}

The haptic magnifier consists in using a serial architecture, where a motor is inserted between the tool and user's hand. By this way, the tool's speed $v_{o}$ can be changed relatively to user's speed $v_{i}$, by controlling motor's speed. If inertial effect can be neglected, then this architecture ensures that at any time, the force applied by the tool $f_{o}$ is equal to the force provided by the user's hand $f_{i}$. The figure 1 describes the serial architecture of the haptic magnifier. The figure 1)a shows the case of a tool directly manipulated by a user, and the case 1)b is the case of the serial architecture. In this example, $v_{o}$ can be lower or higher than $v_{i}$ but we have $f_{o}=f_{i}$.

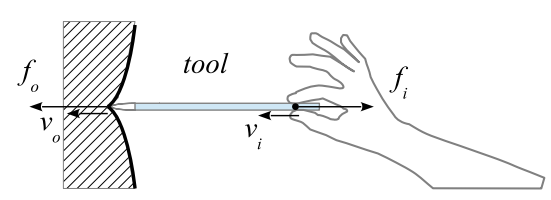

(a)

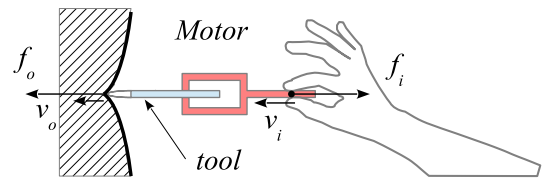

(b)

Fig. 1. A tool manipulated by a user (a) and a serial architecture with a motor inserted to achieve a haptic magnifier(b).

The haptic rendering of the mechanical load is the relationship between force and displacement, i.e. the relationship $f_{o}=F\left(x_{o}\right)$. If no haptic magnifier is used, then the haptic rendering can be summarized by equation 1 :

$$
f_{i}=f_{o}=F\left(v_{o}\right)=F\left(v_{i}\right)
$$

When using the haptic magnifier, the relative speed between the load and the user's hand is controlled by the motor. If we name $k_{M}=\frac{v_{o}}{v_{i}}$ the speed ratio, the force perceived by the user is now given by:

$$
f_{i}=f_{o}=F\left(v_{o}\right)=F\left(k_{M} \times v_{i}\right)
$$


The figure 2 shows an example of a haptic rendering. The force $f_{o}$ depends on the position $x_{o}$, with $\dot{x}_{o}=v_{o}$. In the same way, we define $x_{i}$ the user's displacement. With the haptic rendering, we programmed a ratio $k_{M}<1$, which means that the displacement $x_{o}$ is lower that $x_{i}$. The force $f_{i}$ can be deduced from the equation 2 .

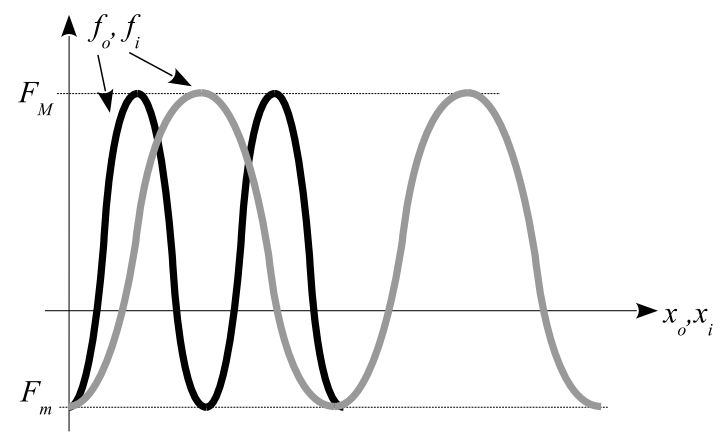

Fig. 2. An example of the resulting force versus displacement for $k_{M}<1 ; F_{m}$ and $F_{M}$ are the maximum and minimum force of the load.

The power $p_{i}$ which is produced by the human user can be compared to the power at the load $p_{o}$ :

$$
p_{i}=f_{i} \times v_{i}=f_{o} \times \frac{v_{o}}{k_{M}}=\frac{p_{o}}{k_{M}}
$$

Hence, the power on the load can be:

- higher than the power at the user's hand if $k_{M}>1$, meaning that user's hand moves slowly compared to the load,

- lower than the power at user's hand if $k_{M}<1$, meaning that user's hand moves faster than the load.

Hence, the haptic magnifier is not a lever. Indeed, when levering a load, the equation 2 is modified, because the ratio $k_{M}$ is applied on the velocity and on the force, and we have $f_{i}=k_{M} f_{o}$. The equation 2 then becomes:

$$
f_{i}=k_{M} f_{o}=k_{M} F\left(k_{M} \times v_{i}\right)
$$

The haptic magnifier changes the perception of a mechanical load attached to a tool, by changing the perceived spatial period. However, it doesn't change the level of the reaction force of the load, in opposition to a lever, which decreases the amount of force when achieving a zoom in of the explored load. We expect from a haptic magnifier that it helps to manipulate a load which contains fine details more easily, by using the magnifying effect. 


\section{Design of the haptic magnifier}

The existing power assist robots, or force feedback devices, are fixed on a base. They work in parallel with the user, and thus, they don't have two terminals required for the tool and for the user. This is why, a specific device has been constructed. The main component of the haptic magnifier is the motor, which modifies the kinematic relationship between the user's input velocity $v_{i}$ and the velocity of the tool $v_{o}$. The speed of the motor is equal to $v_{M}=v_{i}-v_{o}=$ $\left(1-k_{M}\right) v_{i}$. The power produced by the motor is given by $p_{M}=f_{i} \times v_{M}$; the power $p_{M}$ can then be positive or negative, depending on the force $f_{i}$ and the speed differential $v_{M}$. Hence, it actually is a motor which is needed to actuate the tool $\left(p_{M}>0\right)$ or to brake it $\left(p_{M}<0\right)$.

Among the possibilities to actuate the haptic magnifier, Ultrasonic Motors [7] are good candidates since they are more a source of speed than a source of force. Ultrasonic motors use high frequency (above $20 \mathrm{kHz}$ ) and low amplitude vibrations to push a slider by friction. By controlling the amplitude of vibration, we can control the speed of the motor. The device chosen in the experimental realization is a linear PI-Motor M-661 from Physic Instrumente, which is able to drive a load at $2 \mathrm{~N}$ and $0.5 \mathrm{~m} / \mathrm{sec}$.

However, they are not ideal sources of speed. Indeed, if the force in opposite direction to the speed increases, the motor's speed is reduced, with an almost linear behaviour [8]. Closed loop control is thus inevitable. Hence, the experimental setup uses two linear position sensors: one measures $x_{i}$, the position of the input, and the other measures the position of the motor $x_{M} ; x_{o}$ is obtained with $x_{o}=x_{m}+x_{i}$. The experimental setup is presented in figure 3 .
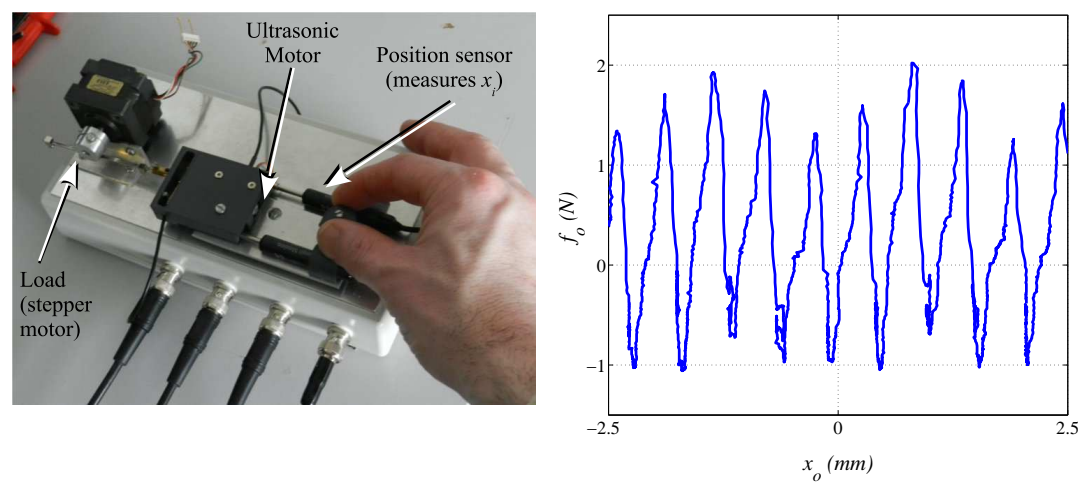

Fig. 3. Realization of the haptic magnifier; left: the experimental setup (the load cell is not visible); right: output force of the load as a function of the position.

To achieve the load, one end of a steel ruler is attached at the output of the haptic magnifier, and the other is attached to the rotor of a stepper motor. The 
stepper motor is never energized; however, when moving the ruler, the rotor of the stepper motor rotates, producing a reaction torque (known as the cogging torque), even though it is not powered. A load cell can measure the force induced by the stepper motor, and the force exerted by the load is presented in figure 3 . The force $f_{o}$ can be positive (the user has to push on the tool to move the load) or negative (the user has to brake the tool to maintain a constant speed), leading to an instantaneous power $p_{o}$ which can be positive or negative. Moreover, fine details are produced by the load. Indeed, 9 stable positions are counted over $5 \mathrm{~mm}$; and equivalent grating with a spatial period of approximately $550 \mu \mathrm{m}$ would give rise to the same amount of stable position.

\section{Experimental results}

We tested the haptic magnifier with a zooming effect only $\left(k_{M}<1\right)$, and figure 4 compares the resulting haptic rendering $f_{i}$ as a function of $x_{i}$ and $f_{o}$ as a function of $x_{o}$ for $k_{M}=0,2$. We still assume that $f_{i}=f_{o}$.

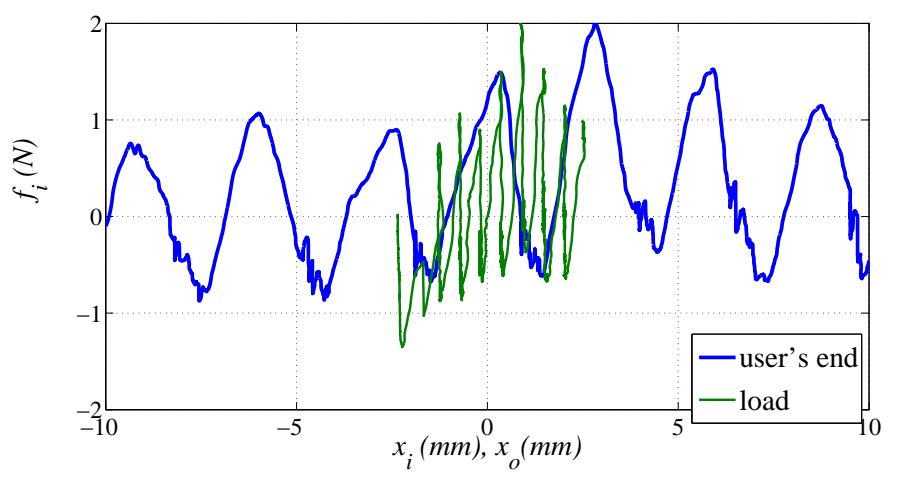

Fig. 4. Resulting rendering for $k_{M}=0.2$; bold blue line is $f_{i}=F\left(x_{i}\right)$ at user's terminal, green line is $f_{o}=F\left(x_{o}\right)$ at the load.

The figure shows how the stable positions of the load are now placed at longer distance from each other on user's point of view. This highlights the property of the haptic magnifier to modify the haptic rendering of the load, without changing the level of its reaction force.

We then asked several users (4 males, 1 females, aged 24 to 31 ) to try the haptic magnifier. The participants were grasping the user's handle with two fingers (between the forefinger and the thumb). In some conditions (conditions 1 and 2), the hand could rest on the table where the tool and the load are lying. In other conditions (condition 3 and 4), the participants were not allowed to rest their hand on the table. In these conditions, moving the user's handle is less comfortable, because user's position is constrained. In conditions 1 and 3 , 
the haptic magnifier is switched off, leading to $k_{M}=1$, and the participants are touching the load through the tool. In conditions 2 and 4, the haptic magnifier is switched on, with $k_{M}=0.2$

During the experiments, the participants followed a training session of about 3 minutes to recognize the load and feel the stable positions, which are named "steps". They are then asked to move the tool 4 steps along forth and backward directions as fast as possible during 80 seconds. We recorded the movement of each participant for the last minute, and we post-processed the number of successful displacements (those with 4 steps only), and the number of overshoots (the displacements which count more than 4 steps). The results are presented in figure 5 .

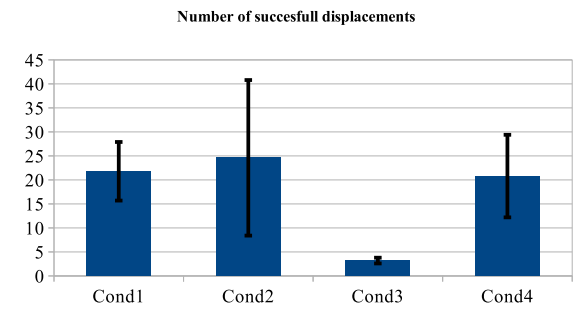

(a)

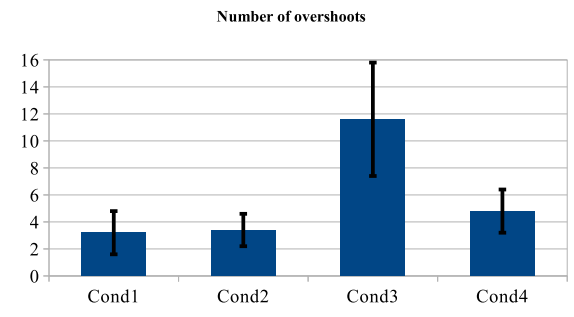

(b)

Fig. 5. Average numbers of successful displacements (a) and overshoots (b) for each experimental condition.

The results show that using the haptic magnifier did not improve the performances of the participants when the hand could rest on the table. Indeed, the average number of successful displacements and overshoots for Conditions 1 and 2 is almost the same. However, the control of the tool is made easier with the haptic magnifier. Indeed, without the haptic magnifier, we noticed that the tips of the fingers which are grasping the user's handle become white, showing that the participants applied larger forces in opposition. To obtain a better control, they are tenser on the user's handle. This effect disappears with the haptic magnifier.

When the hand cannot rest on the table, which constrains more the position of the participant's hand, the participants obtained a very low success rate without the haptic magnifier (condition 3), and they did a large number of overshoots. In fact, some participants could not achieve any successful displacement. In opposition, with the help of the haptic magnifier (condition 4), the participant could obtain a number of successful displacements similar to the conditions 1 and 2, with slightly more overshoots.

At the end of the experiment, we asked the participants to designate the condition which allows them to complete the task more easily. Four participants (out of five) designated the condition 2 (hand on the table and the haptic magnifier). 


\section{Discussion and conclusions}

In this paper, we present the haptic magnifier, which is a serial architecture of a human controlled robot with one degree of freedom. The control of the haptic magnifier allows to change the haptic rendering of a load, without modifying the level of force applied on it. The experimental study shows how the detectable steps of a load can be enlarged to the user's point of view.

The benefit of the haptic magnifier during the exercise depends on the position of the hand. It can improve the comfort of the user when the hand can rest. Or, it can even be necessary to control the tool when the hand does not rest.

Acknowledgments. This work has been carried out within the framework of the Mint Project of Inria, and the Stimtact Project of the Institut de Recherche sur les Composants Logiciels et Matériels pour la Communication Avancée (IRCICA). Financial support for this study was provided by a grant from the European Union which invested in the Nord-Pas-de-Calais Region (FEDER funds) within the framework of the FUI TOUCHIT (Tactile Open Usage with Customized Haptic Interface Technology).

\section{References}

1. Krüger J., Bernhardt R., Surdilovic D., Spur D.: Intelligent Assist Systems for Flexible Assembly. CIRP Annals - Manufacturing Technology 55,1: 29-32 (2006)

2. Kazerooni H.: The human power amplifier technology at the University of California, Berkeley. Robotics and Autonomous Systems 19:179-87 (1996)

3. Üneri A., Balicki M.A., Handa J., Gehlbach P., Taylor R.H., Iordachita I.: New Steady-Hand Eye Robot with Micro-Force Sensing for Vitreoretinal Surgery. Proc IEEE RAS EMBS Int Conf Biomed Robot Biomechatron. Proc IEEE RAS EMBS Int Conf Biomed Robot Biomechatron :814819 (2010)

4. Suphi Erden M., Marić B.: Assisting manual welding with robot. Robotics and Computer-Integrated Manufacturing, Vol. 27,4: 818-828 (2011)

5. Jeon S., Choi S., Stiffness modulation for Haptic Augmented Reality: Extension to 3D interaction. Haptics Symposium, 2010 IEEE , 273-280, 25-26 March 2010

6. Peshkin M.A., Colgate J.E., Wannasuphoprasit W. , Moore C.A., Gillespie R.B.: Cobot Architecture. IEEE Transactions on Robotics and Automation, Vol. 17(4): 377-390 (2001)

7. Ueha, S., Tomikawa, Y., Kurosawa, M., Nakamura, N.: Ultrasonic Motors: Theory and Applications, Clarendon Press, December 1993, ISBN 0-19-859376-7

8. Giraud, F.: Practical considerations in ultrasonic motor selection. Power Electronics and Motion Control Conference (EPE/PEMC), 2010 14th International , pp.T441,T4-44, 6-8 Sept. 2010 